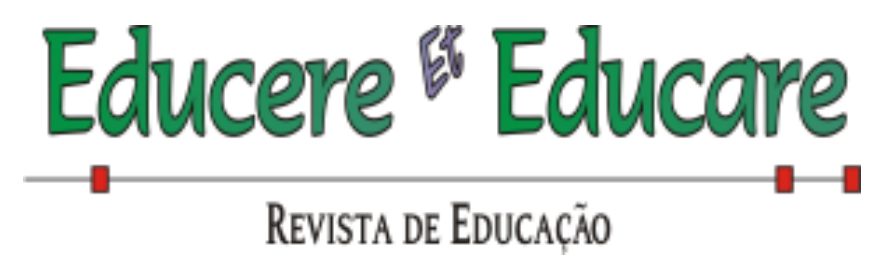

Programa de Pós-Graduação em Educação - Universidade Estadual do Oeste do Paraná

\title{
DESIGUALDADE SOCIAL E JUVENTUDE NA ABORDAGEM SÓCIO- HISTÓRICA: UM BREVE DEBATE SOBRE POLÍTICAS DE AÇÃO AFIRMATIVA
}

\author{
Fernanda de Figueiredo Costa Leiras \\ Mestranda em Educação PPGE/UFMS, Campus Pantanal, Bolsista CAPES \\ Dra. Josiane Peres Gonçalves \\ Universidade Federal do Mato Grosso do Sul/ Campus Pantanal \\ Dra. Beatriz Rosália Gomes Xavier Flandoli \\ Universidade Federal do Mato Grosso do Sul/ Campus Pantanal
}

RESUMO: O presente estudo aborda os conceitos de desigualdade social e juventude na perspectiva sócio-histórica, na tentativa de aproximar estas ideias com a discussão sobre políticas de ação afirmativa, especialmente a política de cotas. A pesquisa bibliográfica fundamenta-se em autores relacionados à área da psicologia sócio-histórica para o debate e reflexões sobre as questões de desigualdade social e juventude, além de artigos com foco nesta mesma temática e pesquisas envolvendo a politica de cotas. Com base no estudo realizado, foi possivel apreender que ainda há muito a se discutir acerca da permanência dos estudantes cotistas após o seu ingresso nas instituições e que a psicologia sócio-histórica pode contribuir para esse debate trazendo a perspectiva e o olhar para estes jovens, como sujeitos históricos que devem participar nesse processo de transformação social do qual fazem parte ativamente.

PALAVRAS-CHAVE: Desigualdade social; juventude; ação afirmativa.

\section{SOCIAL INEQUALITY AND YOUTH IN THE SOCIO-HISTORICAL PERSPECTIVE: A BRIEF DISCUSSION ABOUT POLICIES OF AFFIRMATIVE ACTION}

\begin{abstract}
The present study deals with the concepts of social inequality and youth in the socio-historical perspective, in the attempt to approach these ideas with the discussion on affirmative action policies, especially the quota policy. The bibliographical research is based on authors related to the area of sociohistorical psychology for the debate and reflections on the issues of social inequality and youth, as well as articles focusing on this same theme and research involving the quota
\end{abstract}

policy. Based on the study, it was possible to understand that there is still a lot to be said about the permanence of the quota students after joining the institutions and that sociohistorical psychology can contribute to this debate by bringing the perspective and the look to these young people, as historical subjects who must participate in this process of social transformation of which they actively participate.

KEYWORDS: Social inequality; youth; affirmative action.

Revista Educere Et Educare, Vol. 13, N. 27, jan./abr. 2018. Ahead of Print.

DOI: 10.17648/educare.v13i27.18553 


\section{Educere "Educare \\ Revista de EduCAČ̃̃o}

Programa de Pós-Graduação em Educação - Universidade Estadual do Oeste do Paraná

\section{INTRODUÇÃO}

O presente estudo tem como objetivo apresentar uma reflexão sobre os conceitos de desigualdade social e juventude de acordo com a perspectiva da psicologia sócio-histórica, na tentativa de estender esse debate para o campo da educação e das políticas públicas de ação de afirmativa voltadas para esse grupo. A intenção, para a realização do estudo, é discutir sobre a desigualdade social no Brasil e quais os possiveis impactos que esse contexto pode exercer nas trajetórias educativas de jovens estudantes considerando a atual política de cotas aprovada, em âmbito federal, em 2012.

Com a realização da pesquisa bibliográfica, espera-se contribuir para o aprofundamento de estudos e reflexões acerca das questões relacionadas a desigualdade social e juventude, trazendo a visão da psicologia sócio-histórica.

O estudo encontra-se dividido em 3 subitens, sendo "Desigualdade social: contribuições da abordagem sócio-histórica" no qual será abordada a perspectiva sócio-histórica acerca da desigualdade social na tentativa de desnaturalizar e trazer a tona as condições que a tornaram um fenômeno social; "Adolescência e juventude: contribuições da abordagem sócio-histórica" que trata também de desnaturalizar a adolescência e a juventude ampliando a visão que se tem diante desses que também são fenômenos sociais; "Juventude e políticas de ação afirmativa", que apresenta dados de algumas pesquisas envolvendo estudantes cotistas na tentativa de associar as ideias de desigualdade social e juventude se à implementação das políticas de cotas e levantar questões de como a psicologia sócio-histórica pode contribuir para a compreensão destas políticas levando em conta o contexto histórico e social, bem como a subjetividade daqueles que são envolvidos diretamente nesse processo.

Iniciamos as reflexões com base na perspectiva sócio-histórica que pode nos indicar a condições e os fundamentos da atual visão acerca da 


\title{
Educere Educare \\ ReVISTA DE EduCACÃ̃o
}

Programa de Pós-Graduação em Educação - Universidade Estadual do Oeste do Paraná

desigualdade, considerando a transição do modo de produção feudalista para o modo de produção capitalista, no qual o liberalismo passa a ser a ideologia fundamental e que "[...] tem como um de seus elementos centrais a valorização do indivíduo. [...] Somos indivíduos e somos iguais, fraternos e livres, com direito à propriedade, à segurança, à liberdade e à igualdade.” (BOCK, 2001, p. 18). Assim,

\begin{abstract}
Com essas ideias de igualdade natural entre os homens, o liberalismo propiciou o questionamento das hierarquias sociais e das desigualdades características do período histórico do feudalismo. Ao homem deveriam ser dadas as melhores condições de vida para que seu potencial natural pudesse desabrochar. Diante das enorme desigualdades sociais do mundo moderno, o liberalismo produziu sua própria defesa, construindo a noção de diferenças individuais decorrentes do aproveitamento diferenciado que cada um faz das condições que a sociedade "igualitariamente" lhe oferece. (BOCK, 2001, p. 20)
\end{abstract}

Apesar das aparentes desigualdades de condições que hoje se colocam no Brasil, no que se refere ao acesso a direitos básicos como educação, saúde, cultura e lazer, para citar apenas alguns, essa concepção citada por Bock (2001) contribuiu para a naturalização do fenômeno da desigualdade social, que ainda hoje se encontra presente em discursos que levantam a bandeira da meritocracia levando a responsabilização para o indivíduo sobre sua mobilidade (ou não mobilidade) social. Nesse sentido, a autora afirma que:

[...] a psicologia tem contribuído para responsabilizar os sujeitos por seus sucessos e fracassos. [...] tem reforçado formas de vida e de desenvolvimento das elites como padrão de normalidade e de saúde, contribuindo para a construção de programas de recuperação e assistência destinado àqueles que não conseguem se desenvolver nessa direção (BOCK, 2001, p. 25).

Com base nestas reflexões iniciais, pretendemos estabelecer a discussão deste estudo com o apoio da abordagem sócio-histórica, para melhor compreender a problemática inerente as desigualdades sociais e politicas de cotas. 


\section{Educere "Educare \\ Revista de EduCAČ̃̃o}

Programa de Pós-Graduação em Educação - Universidade Estadual do Oeste do Paraná

\section{METODOLOGIA}

Por se tratar de uma pesquisa bibliográfica, que "[...] é desenvolvida com base em material já elaborado, constituído principalmente de livros e artigos científicos" (GIL, 2002, p. 44), recorremos especialmente a Psicologia SócioHistórica para o debate e reflexões sobre as questões de desigualdade social e juventude; também foram utilizados artigos com foco nesta mesma temática, bem como publicações relativas às políticas de ações afirmativas, que colaboraram com a discussão por meio de dados de pesquisa bibliográfica, na tentativa de enriquecer o trabalho e trazer o debate para os dias atuais.

\section{REVISÃO BIBLIOGRÁFICA}

3.1 Desigualdade social: contribuições da abordagem SócioHistórica

Como a proposta do estudo é realizar uma breve discussão sobre politicas de ação afirmativa, especialmente sobre a política de cotas, Lei 12.711, aprovada em 2012 (BRASIL, 2012), e sabendo-se que essa mesma política atinge majoritariamente jovens estudantes, uma vez que implementa a política de cotas sociais e raciais nas instituições de ensino público federais, sendo as universidades e os institutos federais, entendemos ser necessário abordar inicialmente os conceitos de desigualdade social e de juventude.

Assim, o objetivo deste e do próximo tópico é refletir sobre a perspectiva sócio-histórica para o debate sobre desigualdade social e da juventude, com o intuito de estabelecer uma posterior aproximação entre essas ideias e as políticas de ação afirmativa voltadas a esse grupo.

Ao abordar as questões relativas às desigualdades, Rosemberg (2006, p. 55) destaca que "[...] a desigualdade social no Brasil não é circunstancial mas, ao contrário, é histórica e estrutural". De forma semelhante, Bock et al. (2006, p. 208) afirmam que "[...] para percebermos algo como desigual, precisamos definir 


\section{Educere Educare \\ ReVISTA DE EduCACÃ̃o}

Programa de Pós-Graduação em Educação - Universidade Estadual do Oeste do Paraná

um padrão de igualdade. Esse padrão de igualdade social é contingente e não natural: construído histórica e culturalmente em uma dada sociedade".

Para o enfretamento desse fenômeno, que se coloca cada vez mais latente na sociedade brasileira, cabe problematizar sobre como é produzida e reproduzida a desigualdade social no Brasil. Nesse sentido, Bock et al. (2006, p. 209) salientam que "[...] tradicionalmente, evidenciam-se os aspectos econômicos, sobretudo a diferença na distribuição de renda e no acesso aos bens produzidos", porém alertam que "[...] essa forma hegemônica de estudar o fenômeno exclui todo um processo de transmissão afetiva e emocional de valores, processo invisivel em nossa sociedade, ignorando a gênese cultural da desigualdade $[. .$.$] produzida cotidianamente por meios simbólicos".$

Ainda sobre as condições para a naturalização das desigualdades, Bock (2001) traz as dimensões individuais e sociais para a análise do fenômeno

A questão está em que tais diferenças, em uma sociedade que naturalizou a normalidade, se tornaram fontes de desigualdade e justificativas para desigualdades que são sociais. Desigualdades sociais geram oportunidades diferentes de acesso ao que a humanidade conquistou como possibilidades humanas. A Psicologia registrou essas diferenças como diferenças individuais e, ao naturalizar o desenvolvimento, ocultou a origem social das diferenças (BOCK, 2001, p. 29-30).

Levando essa perspectiva para o campo da educação, os autores questionam a gênese da desigualdade, invertendo a lógica vigente no senso comum

Não é, em princípio, a pouca escolaridade que gera pobreza e desigualdade, apesar de reconhecermos sua importância como aspecto de superação da desigualdade social. É justamente por serem pobres e desiguais que a certas pessoas são destinadas, desde muito cedo, condições objetivas e subjetivas precárias no que se refere à escolarização, o que contribui para retroalimentar sua condição social no mundo (BOCK et al., 2006, p. 226). 


\title{
Educere Educare \\ ReVISTA DE EduCACÃ̃o
}

Programa de Pós-Graduação em Educação - Universidade Estadual do Oeste do Paraná

Considerando essa afirmação, podemos inferir que a educação tem por um lado o papel fundamental de contribuição para a mobilidade social e, por outro lado, pode ser um fator de reprodução e manutenção das condições sociais estabelecidas, não exercendo assim a função de combate a desigualdade social. Podemos perceber, portanto, no campo da educação, uma contradição que se mostra ora pela superação das desigualdades, ora pela manutenção das mesmas, o que torna fundamental a proposta de discussão de Dubet (2003) sobre as finalidades da educação, explicitando essa contradição no âmbito escolar.

\begin{abstract}
Com efeito, a exclusão escolar é o resultado "normal" da extensão de uma escola democrática de massa que afirma ao mesmo tempo a igualdade dos indivíduos e a desigualdade de seus desempenhos. Nesse sentido, a escola integra mais e exclui mais do que antes, apesar de seus princípios e ideologias, e funciona cada vez mais como o mercado, que é, em sua própria lógica, o princípio básico da integração e da exclusão (DUBET, 2003 , p. 44)
\end{abstract}

Souza $(2006$, p. 26) também coloca uma reflexão fundamental sobre o conceito de desigualdade social quando afirma que "[...] tanto o mercado quanto o Estado são perpassados por hierarquias valorativas implícitas e opacas à consciência cotidiana, cuja naturalização, que a traveste de 'neutra' e 'meritocrática', é responsável pela legitimização da ordem social que essas instituições atualizam". Assim, busca compreender os componentes simbólicos e culturais na produção social da desigualdade e do que o autor chama de subcidadania, e desconstruir a ideia de desigualdade social como um processo naturalizado.

Essa questão se torna ainda mais relevante na discussão da desigualdade e do preconceito racial existente no Brasil, especialmente denunciado pelo Movimento Negro a partir da década de 1970, que "[...] tem se empenhado em apontar a desigualdade racial no acesso a bens materiais e simbólicos, a interpretá-la como expressão do racismo estrutural e ideológico, e a propor 


\section{Educere Educare \\ ReVISTA DE EduCACÃ̃o}

Programa de Pós-Graduação em Educação - Universidade Estadual do Oeste do Paraná

políticas que permitam suplantá-la" (ROSEMBERG, 2006, p. 59). Também Moehlecke, com base nas ideias de Florestan Fernandes e questionamentos sobre o mito da democracia racial no Brasil, afirma que "[...] apesar do fim do sistema escravista, a ordem racial permaneceu intacta [...] O antigo regime persistiria na mentalidade, no comportamento, na organização das relações sociais e nas desigualdades entre brancos e negros." (Moehlecke, 2004, p. 764).

Assim, como é preciso combater a naturalização da desigualdade social, também se faz necessário o combate contra a naturalização da desigualdade racial presente no Brasil. Guimarães (1995), teórico das questões raciais históricas, um dos primeiros a debater sobre essa temática no Brasil, coloca de forma clara o desafio existente no país.

O desafio mais crítico para aqueles que lutam contra o racismo no Brasil está justamente em convencer a opinião pública do caráter sistemático e não-casual dessas desigualdades; mostrar a sua reprodução cotidiana através de empresas públicas e privadas, através de instituições da ordem pública (como a polícia e os sistemas judiciário e correlacional); através das instituições educacionais e de saúde pública. Só assim podese esperar levantar o véu centenário que encobre as dicotomias elite/povo, branco/negro na sociedade brasileira (GUIMARÃES, 1995, p. 43).

Podemos observar o empenho desses autores em trazer o aspecto da historicidade e do contexto social para o debate sobre as desigualdades social e racial, afastando-se de concepções que as naturalizem ou que as reduzam a aspectos exclusivamente econômicos, desconsiderando a multiplicidade de fatores que as compõem.

\subsection{Adolescência e juventude: contribuições da abordagem} Sócio-Histórica

Com intuito similar ao acima citado e em contraposição a uma concepção naturalista e universal da adolescência, na qual "[...] desequilíbrios e 


\section{Educere Educare \\ ReVISTA DE EduCACÃ̃o}

Programa de Pós-Graduação em Educação - Universidade Estadual do Oeste do Paraná

instabilidades pressupõem uma crise preexistente no adolescente" (BOCK, 2001, p. 164), visão essa que "[...] negligencia a inserção histórica do jovem, suas condições objetivas de vida" (p. 165), a abordagem sócio-histórica entende a adolescência como uma categoria construída historicamente. Essa revisão de conceito da adolescência foi necessária, uma vez que a psicologia "[...] considerou-a uma fase natural do desenvolvimento, universalizou-a e ocultou, com esse processo, todo o processo social constitutivo da adolescência” (BOCK, 2004, p. 33). Nessa perspectiva, Ozella e Aguiar (2008) argumentam que a adolescência

[...] é criada historicamente pelo homem, como representação e como fato social e psicológico. É constituída como significado na cultura e na linguagem que permeia as relações sociais. Fatos sociais surgem nas relações e os homens atribuem significados a esses fatos; definem, criam conceitos que expressam esses fatos. Quando definimos a adolescência como isto ou aquilo, estamos atribuindo significações (interpretando a realidade), com base em realidades sociais e em "marcas", significações essas que serão referências para a constituição dos sujeitos. (OZELLA; AGUIAR, 2008, p. 99).

Segundo Gusmão (2006, p. 363), “[...] os diferentes são aqueles que, não sendo imediatamente identificados ao modelo socialmente aceito, introduzem na ordem social um ruído capaz de desestabilizar o que se acredita é próprio da vida em sociedade". Os adolescentes ou jovens são um dos grupos que podem ser considerados diferentes neste sentido posto. E, sendo compreendidos dessa forma, a juventude pode ser vista como "[...] um campo de tensão e conflito diante do que se encontra formal e politicamente instituído, não compreendendo o real e a realidade da [...] juventude como resultado das relações entre os homens, da história que se constrói em comum" (p. 364). A autora propõe então uma mudança de concepção:

[...] Nessa concepção de mundo, crianças e jovens são vistos de modo homogêneo, como totalidades definidas por uma razão evolutiva necessária, membros de determinadas categorias de idade, mas nunca por aquilo que são de fato: sujeitos históricos e ativos com relação à vida 


\section{Educere "Educare \\ ReVISTA DE EduCACÃ̃o}

Programa de Pós-Graduação em Educação - Universidade Estadual do Oeste do Paraná

social. [...] O desafio é, então, levar em conta que crianças e jovens são sujeitos socioculturais e, como tal, sujeitos de experiência e de cultura própria. (GUSMÃO, 2006, p. 364).

A abordagem sócio-histórica problematiza a concepção de adolescência compreendida na nossa cultura, que segundo Ozella e Aguiar (2008, p. 100), “[...] a manutenção das concepções de adolescência como um período naturalmente de crise cumpre o papel ideológico de camuflar a realidade, as contradições sociais, as verdadeiras mediações que constituem tal fenômeno".

Sendo assim, essa abordagem traz a tona o questionamento acerca de quais as condições sociais que determinam ou influenciam a construção de uma determinada categoria, no caso deste estudo, a adolescência. Ou seja, se hoje a adolescência é associada a um período de crise, muitos vezes relacionada também à violência, ao uso de drogas e ao individualismo, cabe a reflexão e a busca da compreensão de quais condições levaram a essa construção. (OZELLA; AGUIAR, 2008).

Bock (2001, p. 169) aponta para a contradição condição/autorização e mostra as condições que são postas aos jovens afirmando que "[...] o desemprego crônico/estrutural da sociedade capitalista trouxe a exigência de retardar o ingresso dos jovens no mercado e aumentar os requisitos para esse ingresso, o que era respondido pelo aumento do tempo na escola". Com isso,

[...] O jovem apresenta todas as possibilidades de se inserir na vida adulta, em termos cognitivos, afetivos, de capacidade de trabalho e de reprodução. No entanto, a sociedade adulta pouco a pouco lhes tira a autorização para sua inserção. O jovem se distancia do mundo do trabalho e, com isso, se distancia também das possibilidades de obter autonomia e condições de sustento" (BOCK, 2001, p. 170). 


\section{Educere Educare \\ ReVISTA DE EduCACÃo}

Programa de Pós-Graduação em Educação - Universidade Estadual do Oeste do Paraná

Assim, a autora explica, por meio das condições históricas e sociais, como se constituem as características que compõem a adolescência, como os conflitos, a busca de identidade, a rebeldia.

Ainda sobre a adolescência e juventude, cabe nesse ponto fazer a distinção entre essas duas categorias. Num breve resgate histórico, podemos inferir que a adolescência esteve em predominância no debate público quando do desenvolvimento do Estatuto da Criança e do Adolescente, aprovado em 1990 fruto de intenso movimento social iniciado na década de 1980 e que passa a compreender crianças e adolescentes como sujeitos de direitos e que necessitam de proteção integral (FREITAS, 2005). Durante essa fase, o termo juventude fica fora da prioridade de discussão retomando ainda em meados de 1990, “[...] centrada na preocupação social vividos ou representados pelos jovens, basicamente relacionados às dificuldades de inserção e integração social numa conjuntura marcada pela extensão dos fenômenos de exclusão decorrentes da crise do trabalho (p. 8). A autora ressalta então a relevância de tratar a juventude de forma diferenciada da adolescência e afirma:

As respostas produzidas até então, sob a referência da defesa dos direitos das crianças e dos adolescentes, centradas nos fundamentos da proteção e tutela para garantir um desenvolvimento adequado dos sujeitos até atingir a maioridade, se mostram insuficientes para dar conta das questões emergentes relativas aos processos (e dificuldades) de inserção a atuação no mundo social [...] É nesse sentido, que o tema da juventude, para além da adolescência, se coloca como um novo problema político no país, demandando novos diagnósticos e respostas no plano das políticas. (FREITAS, 2005, p. 8).

Ainda fazendo uma conexão entre a juventude e a desigualdade social, Sposito (2008) nos traz uma importante reflexão sobre o estudante do ensino médio e sua relação com a escolarização, quando coloca que por um lado o jovem de origem desfavorecida enxerga a conclusão do ensino médio como uma vitória e, por outro lado, não tem perspectivas claras com relação ao futuro. 


\section{Educere "Educare \\ ReVISTA DE EduCAC̄̃o \\ Programa de Pós-Graduação em Educação - Universidade Estadual do Oeste do Paraná}

Essa vitória - ultrapassar a barreira do ensino médio - produz um vácuo. Não há perspectivas imediatas de continuidade dos estudos, pois, para a maioria, trata-se de um nivel terminal de escolaridade. Inexiste, também, a garantia do trabalho. Os índices de desemprego juvenil são, significativamente, mais altos do que os da população adulta [...] de um lado o forte reconhecimento de que a escolaridade é fundamental e, ao mesmo tempo, a ausência de sentido imediato para essa escola. (SPOSITO, p. 87, 2008).

Podemos perceber a aproximação da compreensão de Bock (2001), Freitas (2005) e Sposito (2008) quando analisam as condições sociais estabelecidas e que levam a emergência dessa temática, apontando os fatores de "desemprego crônico/estrutural", "crise do trabalho", "indices de desemprego juvenil" como condição essencial e que leva a "dilemas vividos nos processos de busca de construção da inserção, da experimentação, da participação" (FREITAS, 2005, p. 8), dilemas estes não mais vistos como naturais e universais, mas sim com uma origem social e histórica que precisa ser levada em consideração.

Essas mudanças de concepções da adolescência e da juventude, em conjunto com o entendimento da desigualdade social, ambos frutos do contexto histórico e social, levam a novos olhares e a pressões para o planejamento e implantação de políticas públicas sociais que sejam compatíveis com essa realidade.

\subsection{Juventude e políticas de ação afirmativa}

Para iniciar o debate acerca de políticas de ação de afirmativa, em consonância com as concepções anteriormente apresentadas sobre juventude e desigualdade social, cabe anteriormente registrar o entendimento acerca do que são as políticas públicas, recorrendo a Azevedo (2004, p. 26) por entender as políticas públicas.

[...] como qualquer ação humana, são definidas, implementadas, reformuladas ou desativadas, com base na memória da sociedade ou do Estado em que tem curso. Constroem-se, pois, a partir das 


\section{Educere "Educare \\ Revista de EduCAČ̃̃o}

Programa de Pós-Graduação em Educação - Universidade Estadual do Oeste do Paraná

representações sociais que cada sociedade desenvolve a respeito de si própria. As políticas públicas são ações que guardam intrínseca conexão com o universo cultural e simbólico, ou seja, com o sistema de significações que é próprio de uma determinada realidade social. As representações sociais predominantes fornecem os valores, normas e símbolos que estruturam as relações sociais e, como tal, fazem-se presentes nos sistemas de dominação, atribuindo significados à definição social da realidade que vai orientar os processos de decisão, formulação e implementação das políticas.

Assim, a concepção de uma política pública também pode ser compreendida a partir de uma perspectiva sócio-histórica pois se origina por uma questão que se torna socialmente problematizada e que exige portanto do governo uma resposta que atenda aos interesses e demandas predominantes na sociedade (AZEVEDO, 2004).

Com as transformações ocorridas nas concepções de adolescência e juventude, podemos observar importantes movimentos que culminaram na formulação do Estatuto da Criança e do Adolescente em 1990 e do Estatuto da Juventude em 2013, este último que dispõe sobre os direitos dos jovens, os princípios e diretrizes das políticas públicas de juventude e o Sistema Nacional de Juventude, instituindo assim em forma de lei, um olhar diferenciado sobre as necessidades desse grupo.

Analisando neste estudo mais especificamente as políticas de ação afirmativa, podemos afirmar que o Movimento Negro foi uma das forças mais atuantes de pressão social aliado aos estudos sobre desigualdade racial produzidos entre as décadas de 1970 e 1990 (JÚNIOR e CAMPOS, 2106; MOEHLECKE, 2002). Neste contexto, houve tentativas de aprovação de projetos de lei ${ }^{1}$ de ação afirmativa desde os anos de 1980, porém como afirma João Feres Júnior e Luiz Augusto Campos (2016, p. 270), “[...] a introdução de ações afirmativas raciais no país se valeu de uma confluência de pressões vindas das agências internacionais, da academia, do movimento negro e do próprio governo", o que inclui a participação do Brasil na III Conferência Mundial das 


\section{Educere "Educare \\ Revista de EduCAČ̃̃o}

Programa de Pós-Graduação em Educação - Universidade Estadual do Oeste do Paraná

Nações Unidas de Combate ao Racismo, Discriminação Racial, Xenofobia e Intolerância Correlata, em Durban na África do Sul, no ano de 2001, da qual o país saiu signatário.

A partir de então, algumas universidades passam a adotar política de cotas, iniciando com a implementação nas universidades públicas estaduais do Rio de Janeiro em 2002, sendo "[...] crescente o número de universidades que decidiram pelas cotas em dez anos [...] até 2008, 51\% das universidades públicas estaduais e $41,5 \%$ das universidades públicas federais haviam adotado alguma política de ação afirmativa" (SANTOS, 2012, p. 11). Sendo somente em 2012, quando o Supremo Tribunal Federal estabelece a constitucionalidade das ações afirmativas, a aprovação da Lei 12.711 pelo Governo Federal, criando o sistema de cotas nas instituições federais de ensino, com a intenção de promover a representação destes grupos excluídos e assim garantir o seu acesso à educação pública gratuita e de qualidade.

São inúmeras as conceituações para as ações afirmativas, algumas enfatizando a questão da representação de grupos historicamente excluídos em espaços sociais, como mostra Daflon e Júnior (2014, p. 33):

Ações afirmativas são políticas focais que alocam recursos em benefício de pessoas pertencentes a grupos discriminados e vitimados pela exclusão socioeconômica no passado ou no presente. Trata-se de medidas que têm como objetivo combater discriminações étnicas, raciais, religiosas, de gênero ou de casta, aumentando a participação de minorias no processo político, no acesso a educação, saúde, emprego, bens materiais, redes de proteção social e/ ou no reconhecimento cultural.

Outras definições consideram o aspecto temporário da ação afirmativa, o que reafirma a necessidade da discussão acerca de políticas públicas que apresentem soluções estruturais para a questão da desigualdade social. Assim, Guimarães (1997, p. 233) define como políticas de ação afirmativa o, 


\section{Educere "Educare \\ ReVISTA DE EDUCACÃo \\ Programa de Pós-Graduação em Educação - Universidade Estadual do Oeste do Paraná}

[...] aprimoramento jurídico de uma sociedade cujas normas e valores pautam-se pelo princípio da igualdade de oportunidades na competição entre indivíduos livres, justificando-se a desigualdade de tratamento no acesso aos bens e aos meios apenas como forma de restituir tal igualdade, devendo, por isso, tal ação ter caráter temporário, dentro de um âmbito e escopo restrito.

Sob a ótica dos direitos humanos e, especificamente do direito à educação, Piovesan (2006) ressalta a necessidade de especificar o sujeito de direito e afirma que:

[...] determinados sujeitos de direitos, ou determinadas violações de direitos, exigem uma resposta específica e diferenciada. Nesse cenário, as mulheres, as crianças, a população afrodescendente, os migrantes, as pessoas portadoras de deficiência, entre outras categorias vulneráveis, devem ser vistas nas especificidades e particularidades de sua condição social. Ao lado do direito à igualdade, surge também, como direito fundamental, o direito à diferença. [...] percebe-se que as maiores vítimas de violação dos direitos econômicos, sociais e culturais, na experiência brasileira, são as mulheres e as populações afrodescendentes. Daí a necessidade de adoção, ao lado das politicas universalistas, de políticas específicas, capazes de dar visibilidade a sujeitos de direito com maior grau de vulnerabilidade, visando ao pleno exercício do direito à inclusão social (PIOVESAN, 2006, p. 24).

Considerando que a politica pública é concebida a partir de uma situação problematizada e, portanto de conflito “[...] nas formações sociais capitalistas traduz-se na oposição entre os interesses da acumulação e as necessidades dos cidadãos. As politicas sociais, como parte do processo estatal da alocação e distribuição de valores, encontram-se no centro e interesses de classes" (YAMAMOTO, 2009, p. 43).

Assim, podemos buscar uma compreensão acerca das posições que se estabelecem no debate sobre politica de cotas, sem a pretensão de reduzir a discussão, mas como forma de marcar a possivel polarização do debate. De um lado, um discurso de transformação social que está em consonância com o próprio objetivo da política, pautado pela defesa da representação de grupos 


\section{Educere Educare \\ ReVISTA DE EduCACÃ̃o}

Programa de Pós-Graduação em Educação - Universidade Estadual do Oeste do Paraná

excluídos e na redução da desigualdade existente entre diferentes grupos sociais. Por outro lado, um discurso de manutenção do status quo e de resistência às cotas, pautado especialmente no conceito de meritocracia como fundamento para a não aceitação da política de cotas em espaço como a universidade ou escolas federais de ensino médio, historicamente dominadas por grupos socialmente privilegiados.

Dentro deste contexto, o assunto que se tornou central no debate sobre as ações afirmativas envolve a questão racial, que embora seja um dos fatores dentro da política de ação afirmativa, acabou assumindo posição principal especialmente na veiculação de posicionamentos na mídia bem como entre intelectuais. Segundo Santos (2009, p. 53), essa discussão tem três eixos principais, sendo: "i) as ações afirmativas como politica choca o nosso ideal de povo mestiço", uma vez que a identidade nacional foi construída com base no mito da democracia racial, uma política de cotas raciais não teria sentido; "ii) a impossibilidade de definição dos beneficiários de tal política", defendendo a autora o critério de auto classificação racial para o acesso à políticas de ação afirmativa; "iii) a ideia de que as ações afirmativas rechaçam o mérito como direito ao ensino superior", que a autora sugere um questionamento sobre o significado do mérito em uma sociedade que não oferece condições iguais a todos. Nesse ponto, tenta reverter a lógica estabelecida acerca da ideia de mérito.

[...] o sistema de cotas não nos parece que retira o mérito daqueles que tiveram condições materiais de investir na educação dos seus filhos, o que ocorre, entretanto é que eles competem entre os seus iguais, enquanto aqueles que não dispuseram das mesmas oportunidades competem com seus pares, de outro lado. Esta sim, nos parece uma competição mais justa e neste caso, meritocrática (SANTOS, 2009, p. 61).

Ainda na tentativa de compreender os conflitos se colocam no debate sobre política de cotas, Tomasevski (2006, p. 82), com base em pesquisa 


\section{Educere "Educare \\ ReVISTA DE EduCACÃ̃o}

Programa de Pós-Graduação em Educação - Universidade Estadual do Oeste do Paraná

realizada por Ammon em 1957, aponta uma direção se referindo sobre o direito a educação afirmando que:

[...] a exata razão para a exclusão da educação é justamente preservar privilégios. Já em 1957, o primeiro estudo das Nações Unidas sobre discriminação na educação ressaltou como motivação não formalmente declarada justamente o medo de perder privilégio, cujo resultado direto era a negação do direito à educação a potenciais competidores.

Independente da posição que se tome, as instituições passam a ter papel fundamental no debate sobre essas questões, pois como afirma Tomasevski (2006, p. 81), "A escola tende a reforçar estereótipos preconceituosos das vítimas da exclusão e discriminação. A educação está imersa nos valores existentes, mas também ajuda a criar novos valores existentes". Desse modo, compreendendo escola como qualquer instituição educativa, principalmente aquelas que acolhem estudantes cotistas, cabe o questionamento dos desdobramentos da política de cotas para a participação e discussão com toda a comunidade interna e externa, incluindo alunos, professores e funcionários.

Algumas pesquisas apontam para a necessidade permanente de avaliação de como se dá a experiência desses estudantes na instituição, ampliando a preocupação para além do acesso, e sim com sua permanência nas instituições.

Em sua tese de doutorado, Santos (2009) trata a questão da permanência dos estudantes cotistas na Universidade Federal da Bahia e propõe a análise de dois tipos de permanência: a permanência material, que são as condições materiais que permitem o estudante se manter na universidade (compra de material, cópias, alimentação, transporte) e a permanência simbólica, entendida por "[...] condições simbólicas a possibilidade que os indivíduos tem de identificar-se com o grupo, ser reconhecido e de pertencer a ele." (SANTOS, 2009 , p. 71). Os resultados dessa pesquisa apontam que “[...] são inúmeros os 


\section{Educere "Educare \\ Revista de EduCAČ̃̃o}

Programa de Pós-Graduação em Educação - Universidade Estadual do Oeste do Paraná

casos de estudantes que são preteridos, humilhados ou rechaçados por seus professores em sala de aula." (p. 189).

Se por um lado, alguns estudantes são contemplados por ações institucionais visando a permanência, outros lançam mão de estratégias informais para tentar se manter na universidade, como: a cooperação entre os estudantes e suas famílias; o desempenho acadêmico que representa a possibilidade de acesso a bolsas de pesquisa além de proporcionar reconhecimento; a invisibilidade na tentativa de diminuir a possibilidade de ser discriminado; a polarização para a formação de grupos homogêneos que representam maior força no enfretamento das dificuldades; o branqueamento, mencionado por apenas um estudante, mas que pode indicar ser estratégia adotada por outros que se negam a falar; e o enfrentamento que representa o confronto aberto e denúncia, na busca por respeito na comunidade acadêmica. (SANTOS, 2009).

Em dissertação de mestrado sobre as políticas de ações afirmativas na Universidade Federal do Rio Grande do Sul, Bello (2011, p. 123) analisa as trajetórias de vida de estudantes cotistas negros e o processo de resiliência que vivenciam. Em sua conclusão, afirma que os entrevistados "[...] em sua maioria não dão ênfase às próprias dificuldades vivenciadas até a chegada à Universidade, nem mesmo depois que já estão dentro dela, mas sim às oportunidades que tiveram [...]"Identifica, portanto, a resiliência em suas trajetórias uma vez que os obstáculos que enfrentam não os impedem de buscar seus sonhos, e nesse sentido, "[...] eles se tornam mais resistentes, buscam se reestruturar e crescer em resposta às situações de crise e aos desafios do cotidiano." (p.123).

Em outra pesquisa realizada na UFRGS, esta com o objetivo de analisar as práticas institucionais que apoiam a inclusão dos cotistas após sua entrada na Universidade, o que ressaltamos para essa discussão é o que Doebber (2011, p. 151-152) chama de "processos de in/exclusão" visto que "De um lado, é preciso 


\section{Educere "Educare \\ RevisTA De EduCAC̄̃̃o \\ Programa de Pós-Graduação em Educação - Universidade Estadual do Oeste do Paraná}

mostrar a diferença de raça e/ou classe social [...] para acessar a Universidade; por outro lado, após o ingresso, é necessário um esforço cotidiano para diluir as marcas da diferença. Essa seria a condição para permanecer e ter sucesso na Universidade." Nesse sentido, a autora especifica alguns mecanismos que fazem parte dessa in/exclusão:

[...] A estrutura dos cursos permanece praticamente inalterada, tendo sofrido modificações pouco significativas que venham atender de forma satisfatória este novo público que é, em grande parte, composto por outro perfil de estudante. [...] Apesar de o Programa ter como objetivo promover a diversidade no âmbito acadêmico, para se estar na academia é necessário ser como os outros. Nesse sentido, algumas práticas dessa instituição de ensino superior, evidenciadas na estrutura dos cursos, nas estratégias de acolhimento, na didática dos professores, nas formas de avaliação, por exemplo, seguem produzindo mais desigualdades ao não atentarem para as diferenças dos estudantes (DOEBBER, 2011, p. 152).

Bezerra e Gurgel (2012), em pesquisa realizada em alguns cursos de graduação da Universidade Estadual do Rio de Janeiro (UERJ), foram avaliados fatores relativos ao desempenho e evasão por parte dos estudantes cotistas. Os resultados apontam uma equivalência de notas no desempenho entre cotistas e não-cotistas e níveis de evasão menores entre estudantes cotistas, resultados que desmistificam alguns mitos acerca da politica de cotas. Nesse ponto, cabe destacar que a motivação dos estudantes em superar as suas dificuldades iniciais está aliado a programas de apoio e bolsas de incentivo, além do acolhimento dos demais estudantes, professores e técnicos da instituição.

[...] a receptividade favorável ao aluno cotista pode ser um dos grandes responsáveis pelo seu desenvolvimento acadêmico satisfatório ao longo do curso e, consequentemente, pela sua inclusão acadêmica. Já se teve a oportunidade de lembrar os efeitos positivos sobre a motivação daquilo que se chama acolhimento, na linguagem da teoria da motivação. (BEZERRA; GURGEL, 2012, p. 111).

Diante destes estudos, alguns questionamentos surgem no intuito de desvelar os sentidos que estes estudantes cotistas podem atribuir a sua 


\section{Educere Educare \\ ReVISTA DE EduCACÃ̃o}

Programa de Pós-Graduação em Educação - Universidade Estadual do Oeste do Paraná

experiência mediante a política de cotas, mediante seus colegas e professores, mediante a academia: Como esses jovens se veem antes e após o ingresso na instituição? Como iguais? Como diferentes? Como o fenômeno da desigualdade é registrado nestes jovens? E como a psicologia sócio-histórica pode contribuir para a efetivação dos objetivos das políticas de ação afirmativa no Brasil?

Todo o debate e produção científica sobre a política de cotas, parece estar contribuindo para trazer um aumento da consciência da noção de desigualdade social e racial estabelecidas entre os jovens, além de questionamentos acerca da noção de mérito pessoal, mostrando que para que efetivamente haja meritocracia seria necessário o pressuposto da igualdade de oportunidades. Porém, como essas noções são profundamente enraizadas na nossa cultura, podem colocar estes jovens estudantes em situações objetivas e subjetivas contraditórias quando se encontram em espaços que historicamente não foram criados para recebê-los.

Assim, mostra-se fundamental a permanente avaliação da implantação desta política que está extremamente relacionada ao enfretamento das desigualdades sociais presentes no país e tem adolescentes e jovens como alvo principal, considerando as cotas estabelecidas para ingresso no ensino médio federal e nas universidades federais. Na tentativa de aproximar as questões levantadas neste trabalho com a contribuição que a psicologia sócio-histórica pode oferecer com relação a elaboração e avaliação de políticas públicas, Gonçalves (2009, p. 290) afirma que elas,

[...] envolvem as dimensões social e política, afeitas ao campo do poder público, responsável por sua implementação, e ao campo da participação social. Mas envolvem também a dimensão subjetiva de todos os seus atores. A Psicologia tem muito a dizer a esse respeito; e a Psicologia Sócio-histórica propõe que o que se diga leve em conta a historicidade dessa dimensão subjetiva.

Deste modo, a subjetividade é colocada como uma dimensão essencial de análise uma vez que "As condições históricas de nossa sociedade implicam 


\title{
Educere Educare \\ Revista de EduCAC̄̃̃o
}

Programa de Pós-Graduação em Educação - Universidade Estadual do Oeste do Paraná

subjetividades diferentes [...]. As politicas a serem elaboradas devem reconhecer essa realidade e contribuir para sua superação" (GONÇALVES, 2009, p. 291).

Se o acesso a educação superior pública e de qualidade traz impactos não apenas a possibilidades de mobilidade social diante de uma escolarização mais elevada, mas também de abertura de possibilidades de acesso à outras esferas, como uma maior participação na esfera política, por exemplo, podemos inferir que a representação destes grupos antes sub-representados nas universidades, possa começar a exercer uma nova pressão social para a melhoria da política de cotas, especialmente quando se trata das condições de permanência nas instituições de ensino.

\footnotetext{
É impossivel combater as desigualdades nas condições de vida sem o direito à educação. Quando o direito à educação é garantido, opera como um multiplicador, fortalecendo o exercício de todos os direitos e de todas as liberdades individuais, Quando o direito à educação é negado, priva as pessoas de muitos (senão todos) direitos e liberdades. (TOMASEVSKI, 2006, p. 71)
}

Assim, como nos indica Gonçalves (2009), a participação destes jovens é fundamental para o avanço da política de cotas, uma vez que:

\begin{abstract}
A visão que aponta para a historicidade dos fenômenos aponta para práticas voltadas para a promoção dos indivíduos, para seu engajamento na luta por uma vida melhor, contribui para a transformação porque busca a gênese dos fenômenos a serem modificados (vivências, sentimentos, ações) na realidade histórica e material que os constitui; busca explicitar as mediações presentes no processo. (GONÇALVES, 2009, p. 291)
\end{abstract}

Sendo assim, umas das contribuições possiveis da psicologia sóciohistórica está fundamentada na participação destes jovens perante as políticas públicas, ressaltando o compromisso com a transformação social. 


\section{Educere "Educare \\ ReVISTA DE EduCACÃ̃o}

Programa de Pós-Graduação em Educação - Universidade Estadual do Oeste do Paraná

\section{CONSIDERAÇÕES FINAIS}

Com base neste estudo, é possivel apreender que muito se avançou na discussão sobre políticas de ação afirmativa, especialmente, política de cotas, porém ainda há muito o que se discutir. Legitimada, em forma de lei, a questão do acesso às instituições de ensino médio e superior por meio de cotas para grupos sub-representados nestes espaços, cabe agora avançar no debate de como se estabelece a permanência (ou não permanência) destes jovens nestas instituições.

Sabe-se do caráter provisório das políticas de ação afirmativa e a emergência de políticas públicas de longo prazo no campo da educação, porém entendemos que a política de cotas se faz necessária no contexto da educação brasileira para que a representação de grupos historicamente excluídos efetivamente ocorra e assim possam ser devidamente representados em todos os contextos: educação, trabalho, cultura, política, e outros.

Esperamos, com este trabalho, expandir o olhar acerca da contribuição que a psicologia sócio-histórica pode oferecer neste contexto, trazendo a perspectiva e o olhar para estes jovens, como sujeitos históricos que devem participar nesse processo de transformação social do qual fazem parte ativamente, ampliando possibilidades na formulação e avaliação das políticas de ação afirmativa e oportunidades de novas pesquisas acerca deste recente tema na área da educação. 


\section{Educere Educare \\ RevisTA De EduCAC̄̃̃o}

Programa de Pós-Graduação em Educação - Universidade Estadual do Oeste do Paraná

\section{REFERÊNCIAS BIBLIOGRÁFICAS}

AZEVEDO, Janete Maria Lins de. A educação como política pública. 3. ed. Campinas, SP: Autores Associados, 2004.

BELLO, Luciane. Política de ações afirmativas na UFRGS: o processo de resiliência na trajetória de vida de estudantes cotistas negros com bom desempenho acadêmico. 2011. 141f. Dissertação (Mestrado em Educação) Universidade Federal do Rio Grande do Sul, Faculdade de Educação, Programa de Pós-Graduação em Educação, Porto Alegre, RS, 2011.

BEZERRA, Teresa Olinda Caminha; GURGEL, Claudio Roberto Marques. A política pública de cotas em Universidades, enquanto instrumento de inclusão social. Revista Pensamento \& Realidade. Ano XV, v. 27, n. 2, p. 95-117, 2012.

BOCK, Ana Mercês Bahia. GONÇALVES, Maria da Graça Marchina. FURTADO, Odair. (orgs.) Psicologia sócio-histórica: uma perspectiva crítica em psicologia. São Paulo: Cortez, 2001.

BOCK, Ana Mercês Bahia. A perspectiva sócio-histórica de Leontiev e a crítica à naturalização da formação do ser humano: a adolescência em questão.Cad. Cedes, Campinas, vol. 24, n. 62, p. 26-43, abr. 2004.

BOCK, Ana Mercês Bahia. KULNIG, Rita de Cássia Mitleg. SANTOS, Luane Neves. RECHTMAN, Raizel. CAMPOS, Brisa Bejarano. TOLEDO, Rodrigo. A dimensão subjetiva da desigualdade social no processo de escolarização. In: AGUIAR, Wanda Maria Junqueira de; BOCK, Ana Mercês Bahia (Orgs.) A dimensão subjetiva do processo educacional: uma leitura sócio-histórica. São Paulo: Cortez, 2006, p. 207-228.

BRASIL. Lei de Cotas, Lei $N^{\circ} 12.711$, de 29 de agosto de 2012. Presidência da República

Casa Civil, Subchefia para Assuntos Jurídicos. Disponível em: <http://www.planalto.gov.br/ccivil_03/_ato2011-2014/2012/lei/112711.htm>.

Acesso em: 29 nov. 2017.

DAFLON, Veronica Toste; FERES JÚNIOR, João. Políticas da Igualdade Racial no Ensino Superior. Cadernos do Desenvolvimento Fluminense, v. 5, p. 31-43, 2014.

DOEBBER, Michele Barcelos. Reconhecer-se diferente é a condição de entrada - Tornar-se igual é a estratégia de permanência: das práticas institucionais à constituição de estudantes cotistas negros na UFRGS. 2011. 168 f. Dissertação (Mestrado em Educação) - Universidade Federal do Rio 


\section{Educere Educare \\ ReVISTA DE EdUCAC̄̃o}

Programa de Pós-Graduação em Educação - Universidade Estadual do Oeste do Paraná

Grande do Sul, Faculdade de Educação, Programa de Pós-Graduação em Educação, Porto Alegre, RS, 2011.

DUBET, François. A escola e a exclusão. Cadernos de Pesquisa, n.119, p. 2945, jul., 2003.

FREITAS, Maria Virgínia de. Introdução. In: FREITAS, Maria Virgínia de. (Org.). Juventude e adolescência no Brasil: referências conceituais. $2^{\text {a }}$ ed. São Paulo: Ação Educativa, 2005, p. 6-8.

GIL, Antonio Carlos. Como elaborar projetos de pesquisa. 4 ed. São Paulo: Atlas, 2002.

GONÇALVES, Maria da Graça Marchina. A contribuição da Psicologia Sóciohistórica para a elaboração de políticas públicas. In: BOCK, Ana Mercês Bahia (org.). Psicologia e o compromisso social. São Paulo: Cortez, 2009, p. 277-293.

GUIMARÃES, Antonio Sérgio Alfredo. Racismo e anti-racismo no Brasil. Novos estudos, n. 43, p. 26-44, nov. 1995.

GUIMARÃES, Antonio Sérgio Alfredo. A Desigualdade que anula a desigualdade: notas sobre a ação afirmativa no Brasil. In: SOUZA, J. (org.). Multiculturalismo e racismo: uma comparação Brasil-Estados Unidos. Brasília: Paralelo 15, 1997, p.233-242.

GUSMÃO, Neusa Maria Mendes de. Diálogos cruzados: infância, juventude e educação. In: FREITAS, Marcos Cezar de. (org.) Desigualdade social e diversidade cultural na infância e na juventude. São Paulo: Cortez, 2006. p. 363-389.

JÚNIOR, João Feres. CAMPOS, Luiz Augusto. Ação afirmativa no Brasil: multiculturalismo ou justiça social? Lua Nova, São Paulo, n. 99, p. 257-293, 2016.

MOEHLECKE, Sabrina. Ação afirmativa: história e debates no Brasil. Cadernos de Pesquisa. São Paulo, n.117, p 197-217, nov. 2002.

MOEHLECKE, Sabrina. Ação afirmativa no ensino superior: entre a excelência e a justiça racial. Educ. Soc., Campinas, v. 25, n. 88, p. 757-776, Especial, out. 2004.

OZELLA, Sergio. AGUIAR, Wanda Maria Junqueira de. Desmistificando a concepção de adolescência. Cadernos de Pesquisa, v.38, n.133, p. 97-125, jan./abr. 2008. 


\section{Educere Educare \\ RevisTA De EduCAC̄̃̃o}

Programa de Pós-Graduação em Educação - Universidade Estadual do Oeste do Paraná

PIOVESAN, Flávia. Concepção contemporânea de direitos humanos. In: HADDAD, Sérgio; GRACIANO, Mariângela (Orgs.). A educação entre os direitos humanos. Campinas, SP: Autores Associados, São Paulo, SP: Ação Educativa, 2006. p. 11 a 42 .

ROSEMBERG, Fúlvia. Criança pequena e desigualdade social no Brasil. In: FREITAS, Marcos Cezar de. (org.) Desigualdade social e diversidade cultural na infância e na juventude. São Paulo: Cortez, 2006. p. 49-86.

SANTOS, Dayane Brito Reis. Para além das cotas: a permanência de estudantes negros no ensino superior como politica de ação afirmativa. 2009. 214f. Tese (Doutorado em Educação) - Universidade Federal da Bahia. Faculdade de Educação, Salvador, BA, 2009.

SANTOS, Jocélio Teles dos. Introdução. In: SANTOS, Jocélio Teles dos (Org.). Cotas nas universidades: análises dos processos de decisão. Salvador: CEAO, 2012, p. 9-15.

SOUZA, Jessé (org.). A invisibilidade da desigualdade brasileira. Belo Horizonte: Editora UFMG, 2006.

SPOSITO, Marília Pontes. Juventude e Educação: interações entre a educação escolar e a educação não-formal. Educação e Realidade, n. 33, n. 2, p. 83-98, jul/dez 2008.

TOMASEVSKI, Katarina. Por que a educação não é gratuita? In: HADDAD, Sérgio; GRACIANO, Mariângela (Orgs.). A educação entre os direitos humanos. Campinas, SP: Autores Associados, São Paulo, SP: Ação Educativa, 2006, p. 6191.

YAMAMOTO. Oswaldo H. Questão social e políticas públicas: revendo o compromisso da Psicologia. In: BOCK, Ana Mercês Bahia (org.). Psicologia e o compromisso social. São Paulo: Cortez, 2009. p. 37-54.

1 O projeto de Lei n. 1.332, de 1983, não foi aprovado pelo Congresso Nacional. Nele se propunha uma "ação compensatória" para se reparar séculos de discriminação, como bolsa de estudos e reserva de vagas para homens e mulheres negras.

Recebido em: 20/12/2017

Aprovado em: 28/05/2018 